\title{
PRODUÇÃO DE MATERIAL PARA EDUCAÇÃO A DISTÂNCIA: INOVAÇÃO A PARTIR DA CONCEPÇÃO DO BUSINESS MODEL GENERATION
}

CURITIBA/PR MAIO/2018

\author{
Vera Fatima Dullius - FAE - vera.dullius@fae.edu \\ Patrícia da SIlva Tristão - FAE - patricia.tristao@fae.edu \\ Tipo: Relato de Experiência Inovadora (EI) \\ Categoria: Métodos e Tecnologias \\ Setor Educacional: EDUCAÇÃO SUPERIOR
}

\begin{abstract}
RESUMO
O material didático de cada Instituição de Ensino Superior - IES, representa, de alguma forma, o seu posicionamento em relação à concepção pedagógica, percepção de sua responsabilidade na formação integral do cidadão, conhecimento do perfil de público atendido e outros dados que impactam na tomada de decisão no planejamento do desenvolvimento da trilha de formação e do respectivo material didático. A experiência da FAE Centro Universitário está sendo construída a partir do perfil dos discentes, das teorias de ensino-aprendizagem, da diversificação dos meios de compartilhamento e da expertise de uma equipe multidisciplinar de profissionais, cujos docentes reúnem solidez de conteúdo, cuidado relacional no ambiente virtual e aproximação com o mercado de trabalho. O desenvolvimento do desenho de aproximação desse público foi desenvolvido a partir do referencial do Design Thinking com o apoio do recurso do Business Model Generation, que apresenta uma concepção e modelo de planejamento inovadora, utilizando do recurso Canvas para dar expressão gráfica ao modelo.
\end{abstract}

Palavras-chave: EAD. Trilha. Design Thinking. Business Model Generation. Canvas. 


\section{Introdução}

A educação a distância no ensino superior brasileiro está cada vez mais sujeita a diversificação de modelos de oferta (produtos e serviços) como esforço de atender os objetivos das instituições e da demanda proveniente de seu público. Esta realidade é explicitada pelos resultados do censo[1] da Associação Brasileira de Educação a Distância (ABED, 2017) e das temáticas dos congressos internacionais ocorridos anualmente, pelos dados do Censo do Ensino Superior (INEP, 2017) e decorrente de análises conjunturais realizadas pelas entidades do segmento.

A ampliação da oferta estimulada pelo teor do Decreto no 9.057 (BRASIL, 2017) evidencia reações controversas, tendo em vista os distintos propósitos educacionais: corrida desenfreada por redução de valores de mensalidades, indicação de endereços para novos polos apenas como estratégia de garantia antecipada de espaços geográficos, reengenharia de recursos humanos, desde a tutoria à produção de material, redução de custos a partir de novos modelos de vínculo de tutor/autor etc. Por outro lado, encontramos um conjunto de IES reorganizando-se para expandir, mas preservando qualidade, evitando a concorrência resumida no preço, buscando estratégias para desenvolver recursos e serviços para o aluno conciliando sustentabilidade, expansão da oferta e atendimento qualificado.

O presente relato visa explicitar aspectos do paradigma de gestão do NEAD e o fluxo de desenvolvimento de material para disciplinas ofertadas pela FAE na condição de $20 \%$ em EAD nos cursos de graduação presencial e apresentar um dos recursos utilizados para mapear informações sobre o perfil de alunos.

Entende-se que mapear e conhecer adequadamente o perfil dos alunos, utilizando-se do recurso do "Mapa da Empatia", permite a articulação da proposta com o desenho da concepção dos padrões de qualidade do material desenvolvido em diferentes mídias para ser disponibilizado ao aluno (OSTERWALDER; PIGNEUR, 2011, p. 130-133).

Este processo utiliza-se da concepção do Business Model Generation (OSTERWALDER; PIGNEUR, 2011) e das ferramentas e recursos propostos pelos autores para promover a organização das ideais e modelagem do negócio. A concepção de "modelo de negócio" pode ser utilizada na gestão do Núcleo de Educação a Distância - NEAD.

\section{Objetivos}


O presente artigo tem como objetivo compartilhar brevemente a concepção e fluxo de desenvolvimento do material didático para educação a distância, apontando as ressonâncias que o modelo apresenta na formação dos egressos dos cursos a partir da participação dos diferentes atores da comunidade acadêmica: autores, responsáveis de área, tutores e equipe multidisciplinar de criação e desenvolvimento dos recursos. Propõe-se, ainda, a sustentar a visão da abordagem do Business Model Generation (OSTERWALDER; PIGNEUR, 2011) como paradigma referencial para e gestão da oferta de EAD e do desenvolvimento dos recursos utilizados na trilha disponibilizada no ambiente virtual de aprendizagem.

\section{Referencial teórico}

O desenvolvimento de material para a educação a distância tem sido alvo de grande debate pelas IES, fábricas de conteúdo, consultorias e agências de avaliação e regulação. O debate nasce das perspectivas de projeção da escala de atendimento em relação ao perfil do público atendido, à disposição de cada segmento de mercado, ao ticket de mensalidade e ao resultado final como produto-serviço educacional.

O que está na essência da reflexão proposta é a necessidade da gestão das instituições apropriarem-se de paradigmas de gestão inovadoras, alinhadas com as mudanças no conjunto de variáveis que configuram o cenário EAD (RIBAS, 2014) e que acabam refletindo diretamente no que se constituiu o processo de desenvolvimento das trilhas e dos recursos. A concepção de EAD e de ensino-aprendizagem deverá desafiar os gestores a conhecerem: relação do perfil do público e entrega de valor (OSTERWALDER; PIGNEUR, 2011), aspectos que geram qualidade e diferenciação, métricas de produtividade por perfil profissional, custos e outros elementos que contribuem na tomada de decisão sobre qual o público a ser atendido e qual a proposta de valor que pretende-se entregar, o que marcará a identidade da IES.

Reafirma-se que existe demanda para todos os perfis de público e a carência de Ensino Superior no Brasil é evidente. Sendo assim, é preciso ter claro que a questão do posicionamento da IES é critério determinante para desencadear a análise sobre qual será o seu modelo de negócio, fundamentos apresentados por Alexandrer Osterwalder e Yves Pigneur a partir do livro Business Model Generation (2011). Tal abordagem está sendo utilizada em diferentes segmentos e muito contribui para pensar a vida das organizações, o papel do EAD e seu lugar de missão na sociedade.

Caso a opção da IES seja por um público sensível ao preço de mensalidade (mais baixas) e a IES pretenda capilarizar-se nacionalmente por meio de polos, a opção pelo 
tipo de material didático e a forma de produção passará por padronizações cujo critério balizador será a redução de custo operacional de produção, projetando como alternativa a estrutura própria ou buscando fábricas de conteúdo parceiras, considerando escala e abrangência, assim como a opção por plataformas de gestão de conteúdos e do Learning Management System - LMS.

É fundamental vencer critérios antecipados e preconceituosos, como, por exemplo, sobre o tipo de material, origem da produção (própria ou terceirizada), entre outros, ao analisar a correlação sobre o que está sendo ofertado, para quem, como e por quê. Importa revisar o conceito de material didático, a diversidade de recursos e as suas funções pedagógicas, conforme contribuições de Bates (2016, p. 289-384).

O aspecto crucial é que, dentro do custo operacional prospectado para o projeto EAD, seja garantida a qualidade mínima para respeitar a expectativa do público atendido, ou seja, independente de qual classe social atendida, espera-se que o material - entendase o conjunto de objetos de aprendizagem disponíveis na trilha de formação - tenha requisitos mínimos de qualidade: coerência com a proposição do perfil de egresso anunciado pela IES, densidade compatível com o ensino-aprendizado a distância em função da carga horária da disciplina, linguagem adequada, correção das informações, múltiplas linguagens, processo de avaliação coerente e que apure adequadamente os domínios teórico-práticos do aluno.

Devemos considerar que o relato de experiência aqui apresentado nasce em uma IES que atende a um público com um perfil singular: expectativa de alto valor agregado na formação recebida por meio da efetiva atuação mediadora dos professores, valorização da experiência de mercado da maioria dos docentes, conteúdos alinhados ao contexto e as práticas profissionais, modelo de acompanhamento e avaliação compatível com a proposta, entre outros aspectos.

Tendo em vista o atendimento do perfil de aluno da graduação da instituição, as opções quanto às características do desenvolvimento de material seguem um rigor diferenciado quanto ao valor que se pretende entregar. $O$ entendimento do público é trabalhado utilizando uma ferramenta chamada "Mapa da Empatia[2]" como prática contínua, além das informações extraídas nas avaliações da Comissão Própria de Avaliação - CPA.

A proposta pedagógica da instituição está alicerçada na concepção de que a formação do ser humano deve ser integral, embasada em princípios e valores que ofereçam a base para desenvolver as competências preconizadas no perfil do egresso de seu curso e que promovam canais para a empregabilidade. O modelo peculiar de propor uma 
formação preocupada com a especificidade das competências demandadas pelo contexto do mundo do trabalho exige que os profissionais que atuam na educação a distância estejam em constante processo de atualização acadêmica, apropriação das inovações tecnológicas e adequação didática para promover crescente aprendizagem. Uma comunidade acadêmica formadora que se coloca como aprendente gera novas estratégias de ensino-aprendizagem, com metodologias que despertem nos estudantes o melhor de si para o desenvolvimento de competências, habilidades e atitudes, tanto presencial como a distância, sem diferenciações de qualidade de material ou serviço prestado pelas pessoas.

Os profissionais que atuam em um projeto (disciplina) são desafiados a articular conteúdos com base teórica sólida, a incorporar as novas demandas do mundo do trabalho, aprimorar de forma permanente a criatividade, flexibilidade e capacidade de otimização dos recursos disponíveis. Os autores de conteúdo são profissionais da própria instituição, os quais partem de uma ementa da disciplina comum às disciplinas da oferta presencial (utiliza-se aqui a diferenciação entre a distância e presencial para fins de compreensão do que utilizamos usualmente) e, por meio da interação com a Desenhista Instrucional, desenvolvem todos os elementos que integram o conjunto de recursos que fazem parte da trilha de ensino-aprendizagem da disciplina ofertada a distância por meio de seus distintos objetos de aprendizagem: texto base, guia de estudos, telas interativas, vídeos, atividades, fóruns, videoconferência, proposta avaliativa, midiateca, entre outros.

Todos os esforços visam promover o conhecimento no espaço acadêmico e, segundo Bates, algumas características são essenciais: "transparência, codificação, reprodução e comunicabilidade" (BATES, 2016, p. 105).

\subsection{Pressupostos do Business Model Generation no planejamento}

A abordagem teórica do Business Model Generationnasce da concepção inovadora de modelo de negócios, a qual difere muito do paradigma do plano de negócios, quando diz que: "um modelo de negócios descreve a lógica de criação, entrega e captura de valor por parte de uma organização" (OSTERWALDER; PIGNEUR, 2011, p. 14).

A sua origem já é marcada pela diferenciação, pois Osterwalder e Pigneur desenvolvem de forma colaborativa essa metodologia e garantem que, muito além de teoria, é uma forma diferente que "mostra a lógica de como uma organização pretende gerar valor" (OSTERWALDER; PIGNEUR, 2011, p. 15). 
A abordagem utiliza várias ferramentas responsáveis pelo envolvimento ativo das pessoas que fazem parte do planejamento. A configuração das ideias ocorre por meio do preenchimento de um quadro chamado Canvas[3]. Este possui nove blocos, conforme quadro a seguir:

A tela de modelo de negócios

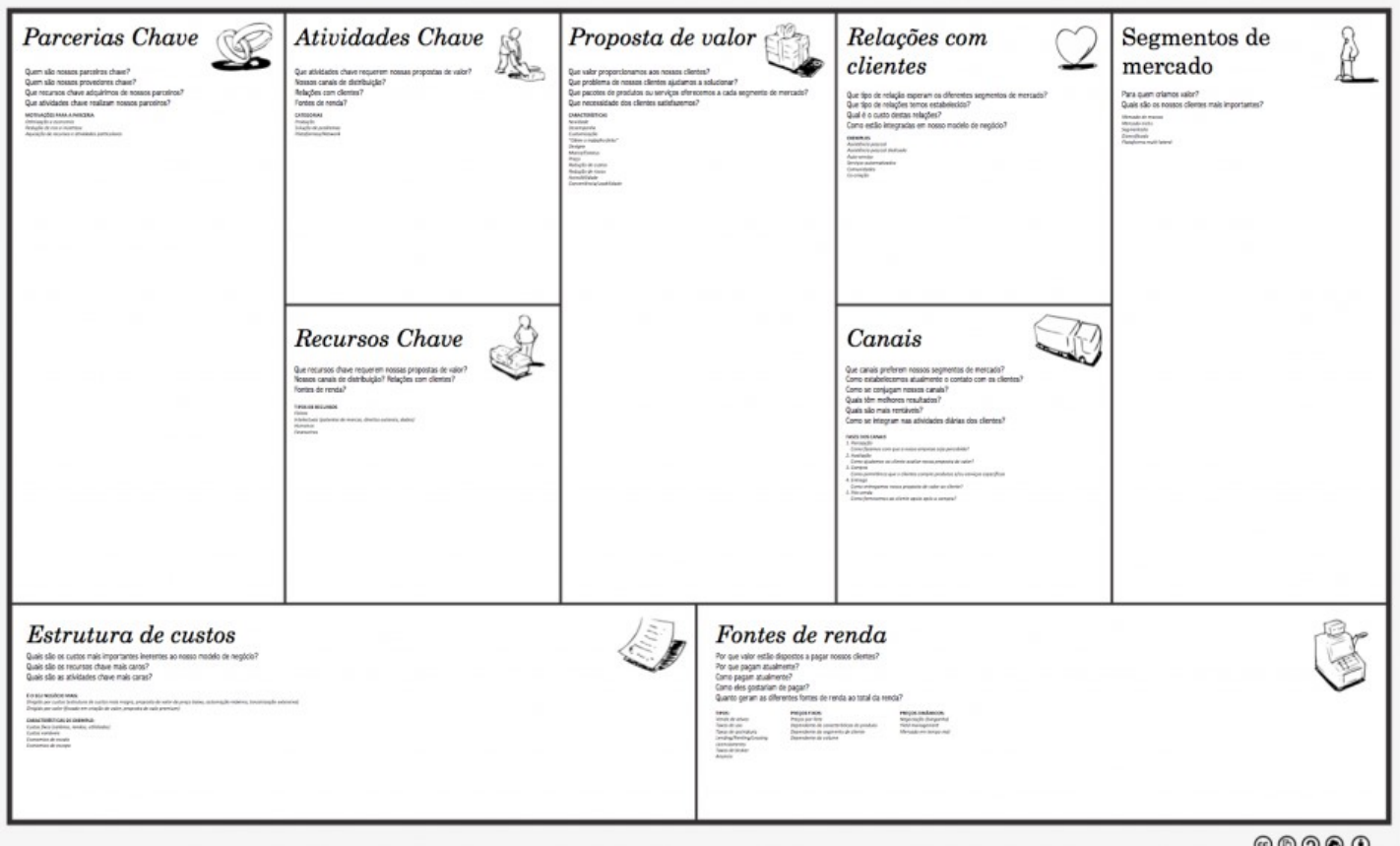

Fonte: Sebrae (2013)

O artigo explora dois blocos do Canvas: a definição do público alvo e a entrega de valor. É fundamental a IES ter claro em seu planejamento estratégico em qual contexto pretende atuar: contexto de massa, em segmento específico, multivariado ou de nicho, esclarecendo, assim, qual segmento de clientes buscará atender (OSTERWALDER; PIGNEUR, 2011). Acrescidas as definições internas, é preciso considerar, em primeiro lugar, qual é a sua prerrogativa de autorização legal para oferta a distância. Essas definições encaminharão para opções que decorrem de abrangência geográfica, infraestrutura demandada para a escala prospectada, processo de produção, de objetos de aprendizagem, parcerias; enfim, o detalhamento de todos os blocos que explicitam o modelo de negócios, indicado no Canvas.

\subsection{Escopo do modelo de oferta da IES}

O rol de disciplinas ofertadas na modalidade a distância na FAE visa proporcionar aos 
alunos a diversificação e flexibilidade curricular. A adesão às disciplinas ocorre de forma espontânea e opcional. Os grupos de alunos constituídos nas disciplinas são provenientes de distintos cursos e as respectivas disciplinas escolhidas são de sua grade curricular, equivalentes ou atendem ao requisito de enriquecimento curricular.

A demanda pelo rol de disciplinas é apontada pelo Coordenador de Curso, que identifica disciplinas potenciais. A indicação de tais componentes transita em fóruns competentes, são validados pela Reitoria, passam a integrar um Edital para captação de autores internamente e, na falta de disponibilidade interna, abre-se edital externo. Após a decorrência do processo de seleção e capacitação, os profissionais assumem um cronograma para desenvolvimento do material didático. Todos os processos são descritos a partir do desenho e gestão de processos do BPMN (Business Process Management), conforme o exemplo:

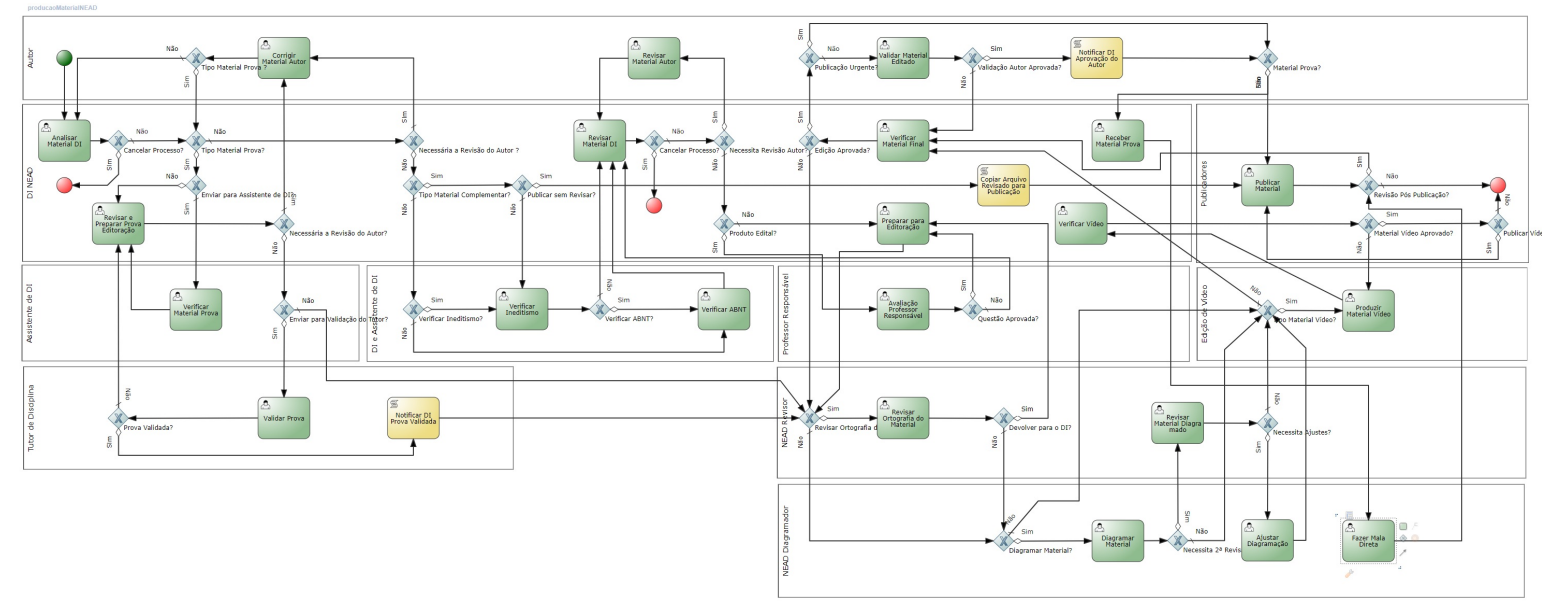

\section{Procedimentos metodológicos}

A abordagem metodológica para a aproximação do contexto investigado é a fenomenológica, com pesquisa qualitativa utilizando ferramentas específicas para a modelagem, ou seja, o Design Thinking. Conforme Filatro é uma "abordagem que catalisa a colaboração, a inovação e a busca por soluções mediante a observação e a cocriação, a partir de prototipagem rápida e da análise de diferentes realidades" (CAVALCANTI; FILATRO, 2007, p. 20). Tal modelo mental propõe uma forma específica de se aproximar do fenômeno investigado, conhecer o contexto, o público, rede de influências e outros elementos que contribuem para conhecer o segmento e, a partir daí, compreender e iniciar a modelagem de soluções.

\section{Apresentação e discussão dos resultados}

A instituição está desenvolvendo as trilhas e objetos de aprendizagem das disciplinas de 
tal forma que não há diferenciação qualitativa entre a oferta presencial e a distância na IES. A diversidade de recursos (objetos de aprendizagem) estão, também, disponíveis para alunos em situação de matrícula presencial por meio de um repositório de conteúdos próprio da IES.

O material didático desenvolvido entrega soluções marcadas pela diferenciação, exclusividade, atualização, flexibilidade e densidade teórica (OSTERWALDER; PIGNEUR. 2011, p. 22-25). A partir da mediação da tutoria, ocorre a exploração dos objetos no ambiente virtual de aprendizagem. Os tutores são docentes da instituição e também atuam na docência presencial.

As pesquisas da CPA, os diálogos presenciais, a aplicação de ferramentas de avaliação e pesquisa de satisfação na sala virtual moodlerooms permitem perceber que há a aceitação do material didático e o reconhecimento de que são suportes de estudo adequados para o acompanhamento da proposta curricular. O processo é acompanhado e avaliado pela equipe multidisciplinar de desenvolvimento e cumprem métricas de produtividade, as quais permitem à IES ter claro qual é a capacidade instalada de desenvolvimento para absorver novas demandas. Reafirma-se que a qualidade diferenciada também imputa em tempo específico para o desenvolvimento.

A tomada de decisão de qualquer IES considera o triângulo de elementos: perfil do segmento atendido, entrega de valor e custo/receita para que ocorra uma gestão sustentável do processo.

\section{Considerações finais}

A sociedade globalizada, o aparato das mídias sociais, formas alternativas de comunicação, oferta de produtos e serviços internacionais, o investimento de grandes grupos educacionais em educação a distância e a oscilação econômica e legal na área da oferta EAD são variáveis que são colocadas, de forma especial para as pequenas e médias IES repensarem seu lugar no cenário do ensino superior no Brasil e, mais do nunca, afirmarem seu perfil de atuação em EAD.

A FAE atua há mais de 60 anos no Ensino Superior e reafirma que o seu posicionamento de excelência exige atenção para os aspectos da diferenciação, customização, diversificação e flexibilidade, que são critérios avaliativos de qualidade (BATES, 2016, p. 462) quanto ao perfil do material didático desenvolvido e, por consequência, do perfil dos autores, tutores e equipe multidisciplinar do EAD. 
O Business Model Generation (OSTERWALDER; PIGNEUR, 2011) é um bom referencial para pensar fora do padrão, do lugar comum, da disputa pela atuação nos mesmos contextos, com os mesmos recursos já testados por outros, superando a tendência de repetir as experiências. A abordagem permite consolidar a convicção de que há um público a ser atendido e, para esse público, é preciso entender a proposta de valor, o que pretende-se entregar como resposta à expectativa desse público, considerando o que está disposto a suportar de custo por esse produto ou serviço. Os estudos na área de empreendedorismo, dimensão que está impregnada no DNA da FAE, é um importante impulsionador de ensaios de novos modelos do Núcleo de Educação a Distância.

\section{Referências}

ASSOCIAÇÃO BRASILEIRA DE EDUCAÇÃO A DISTÂNCIA - ABED. Censo EAD Brasil 2016: Relatório analítico de aprendizagem a distância no Brasil. Curitiba: InterSaberes, 2017.

CAVALCANTI, Carolina Costa; FILATRO, Andrea. Design thinking na educação presencial, a distância e corporativa. 1. ed. São Paulo: Saraiva, 2007.

BATES, A. W. (Tony). Educar na Era Digital: design, ensino e aprendizagem. 1. ed. São Paulo: ABED; Artesanato Educacional, 2016.

BRASIL. Decreto no 9.057, de 25 de maio de 2017. Regulamenta o art. 80 da Lei ํo 9.394, de 20 de dezembro de 1996, que estabelece as diretrizes e bases da educação nacional. Diário Oficial da União, Brasília, 2017. Disponível em: <http://www.planalto.gov.br/ccivil_03/_ato2015-2018/2017/decreto/D9057.htm>. Acesso em: 18 maio 2018.

INSTITUTO NACIONAL DE ESTUDOS E PESQUISAS EDUCACIONAIS ANÍSIO TEIXEIRA. Sinopse Estatística da Educação Superior 2016. Brasília: Inep, 2017. Disponível em:<http://portal.inep.gov.br/basica-censo-escolar-sinopse-sinopse>. Acesso em: 18 maio 2018.

OSTERWALDER, Alexander, PIGNCUR Yves. Business Model Generation: Inovação em Modelos de Negócios: um manual para visionários, inovadores e revolucionários. Rio de Janeiro: Alta Books, 2011.

QUAISER, Paula. Mapa de Empatia, o que é? Canvas Academy. Disponível em: 
<http://canvasacademy.com.br/mapa-de-empatia-2/>. Acesso em: 05 maio 2018.

RIBAS, Júlio Cesar. Planejamento por cenários prospectivos na Educação a Distância. Jundiaí: Paco Editorial, 2014.

SEBRAE. O quadro de modelo de negócios: um caminho para criar, recriar e inovar em modelos de negócios. 2013. Disponível em: <https://www.sebraecanvas.com.br/downloads/cartilha_canvas.pdf>. Acesso em: 07 maio 2018.

[1]ASSOCIAÇÃO BRASILEIRA DE EDUCAÇÃO A DISTÂNCIA - ABED. Censo EAD Brasil 2016: Relatório analítico de aprendizagem a distância no Brasil. Curitiba: InterSaberes, 2017.

[2] Mapa da Empatia. Disponível em: http://canvasacademy.com.br/mapa-de-empatia-2/ Acesso em 5/05/2018.

[3] Disponível em: https://www.sebraecanvas.com.br/downloads/cartilha_canvas.pdf ou https://endeavor.org.br/business-model-generation-artigo/ Acesso em 7/05/2018. 